\title{
NURSING INFORMATICS EDUCATION AND USE: CHALLENGES AND PROSPECTS IN NIGERIA
}

\author{
GRACE C. ROBINSON-BASSEY AND OLAIDE B. EDET
}

(Received 30 April 2015; Revision Accepted 11 September 2015)

\begin{abstract}
In order to function in the increasingly complex healthcare environment, every nurse is required to have basic computer competencies, be able to access, use and evaluate relevant nursing information and possess information management skills. Nurse Faculty, Nurse/Midwife educators are vested with the responsibility of producing the crop of nurses who have the capabilities to fit into the current trend of nursing practice. Literature has shown that comprehensive informatics content is lacking in the nursing curricular at all levels of nursing education in Nigeria. There is preponderance of evidence showing that training in $\mathrm{NI}$ is critical in the delivery of safe and quality patient care. This paper examines the current state of nursing informatics education and use in Nigeria and proffer solutions for its future expansion. It is recommended as follows: Nursing programme accrediting bodies in Nigeria (National University Commission [NUC] and Nursing and Midwifery Council of Nigeria [NMCN] should modify their requirements to reflect the value of NI. NI should be incorporated into the nursing curricular at all levels. Nursing administrators such as Deans, Heads of Department, Director of Nursing Services and Principals as well as Nursing associations like National Association of Nigerian Nurses and Midwives [NANNM] and Nigerian Association of University Nursing Programme [NAUNP], should create opportunities for faculty members, Nurse/Midwife educators to develop knowledge \& skills required to teach nursing informatics. Faculty members \& Nurse/Midwife educators should acquire informatics training and advocate for curricular changes that incorporate informatics and collaborate with colleagues in the clinical settings to provide opportunities for nursing students to utilize informatics tools.
\end{abstract}

KEY WORDS: Nursing informatics, Nursing informatics education, Competencies, Health informatics.

\section{INTRODUCTION}

The use of Information Technology [IT] in healthcare with a focus on information management rather than on computers is known as health informatics (Sewell \& Thede, 2013). This super high way has greatly impacted health care resulting in more and more clients becoming well informed about their health concerns. It is therefore obligatory for the nursing workforce in Nigeria to keep pace with the world-wide trends in health care delivery, which is tailored to the utilization of Information Communication Technology (ICT) in service delivery. Information Communication Technology (ICT) is a process of transmitting media data from a source to a destination through electronic means. Nursing service delivery in the present dispensation demands a combination of nursing science, computer science and information science in relation to the diagnosis and treatment of human response to health \& illness which has been defined as Nursing Informatics [NI] (Tellez, 2012). Nurse educators are vested with the responsibility of producing the crop of nurses who have the capabilities to fit into the current trend of nursing practice. Although $\mathrm{NI}$ has many multifaceted competency requirements, in order to function in the ever increasingly complex healthcare environment, every nurse is required to have some basic competencies. These are computer competencies, capacity to access, use and evaluate appropriate nursing information and possess information management skills (Gugerty \& Delane, 2009). This paper focuses on the current status of nursing informatics education and its use in Nigeria. Recommendations are made for its expansion.

\section{HEALTH-CARE INFORMATICS /HEALTH INFORMATICS}

The expression medical informatics was changed to healthcare/health informatics when some health professionals opined that the term was restricted to only physicians (Shortliffe \& Blois, 2006). However, both expressions are still used interchangeably even today. Health-care informatics is interdisciplinary in nature. Its central focus is patient care and not a particular disciplines (Hannah, Ball \& Edwards, 1999). Although each profession in the health-care team, such as nursing, dentistry, dietetics, pharmacy, medicine, radiography have their specific bodies of knowledge, they are all connected to the patient. Its main focus is on managing information in healthcare. The purpose is to bring about improvement in the way healthcare data, information and knowledge is used, to support patient care research and education (Delaney, 2001).

Shortliffe \& Blois (2001) affirmed that healthcare informatics is an umbrella terminology, which describes the "capture, retrieval, storage, presenting, sharing \& use of biomedical information, data \& knowledge for providing care, problem solving and decision making".

Grace C. Robinson-Bassey, Department of Nursing Science, University of Port Harcourt, Port Harcourt, Nigeria.

Olaide B. Edet, Department of Nursing Science, University of Calabar, Calabar, Nigeria. 
O'Caroll et al (as cited in Idowu, Cornford and Bastin, 2008) defined health informatics as a demonstration of how organizations can utilize IT to progress their strategic goal from theory to practice. Health informatics has also been defined as the science that deals with the application of information systems which allow collection, updating, storing, analysis and management of health related data in order to assist health care delivery (Idowu et al., 2008). Shortliffe \& Blois (2006) grouped health informatics into seven domains namely; Clinical informatics, Veterinary informatics, Dental informatics, Bioinformatics, Imaging informatics, Public Health informatics and Nursing informatics. The last domain is the focus of this paper.

The beginning of health informatics in Nigeria has been traced to $1988-1989$ which witnessed a collaborative project between Computing Center of the University of Kuopio, Finland and Obafemi Awolowo University and Obafemi Awolowo Teaching Hospital (OAUTH), Nigeria (Idowu et al, 2003; Ohanyido, 2012). The project was an offshoot of a research on Informatics Development for Health in Africa [INDEHELA] (INDEHELA, 1989). The project led to the establishment of a rudimentary health information system on Admission, Discharge \& Transfer of patients, using a stand-alone PC at Obafemi Awolowo Teaching Hospital in 1991 (Dani et al, 1992). The project culminated in the first International Working Conference on Health Informatics in Africa which was held from 19-23, April, 1993 at Ile-Ife, Nigeria (Mandil, 1993; Mandil et al, 1993).

In the late 1990s, the Finnish/Nigerian research team decided to upgrade the rudimentary information system to a comprehensive system which could be used by health facilities in Nigeria. This resulted in the development of a made in Nigeria "Primary Healthcare and Hospital Information System" (MINPHIS) in 2004. The commercial software which was expensive could only be used by five teaching hospitals and medical centers as at 2007 (Idowu et al, 2008). In addition to this effort, a Norwegian and South African team also focused on district level information management system (Anja, 2002). District Health Information System 2 (DHIS 2) was established as a tool for collection, validation, analysis and presentation of aggregate statistical data. It is an open source software developed by the Health Information Systems Programme (HISP) as an open and globally distributed process. By 2012 the software was in use in more than 30 countries and has been adopted for use in Nigeria (FMOH, 2014).

The Health and Demographic System (HDSS) is a tool aimed at generating data on key demographic events such as births, deaths and some burden of disease indicators. The software in use is the Open Health and Demographic Surveillance software (OpenHDS) which was developed by the University of Maine which is available throughout Africa. Nigerian stakeholders had insisted that the software be linked to the National Health Information System, thus making it possible for data to the transferred from the local government to the state and to the federal level. Three sites have been established in Nigeria. These are Nahuche HDSS in Bungudu Local Government Area (LGA), Cross-River HDSS in Akpabuyo LGA and Oriade HDSS in Oyo State. The pilot study covering 1370 households has been completed in Cross River State. The activities of the HDSSs are co-ordinated by the International Network for the Demographic Evaluation of Populations and Their Health (INDEPTH)(Ye et al (as cited in Arikpo, 2013); IDRC/CRDI, 2013; Arikpo et al, 2013).

Other non-commercial software packages were also developed for Nigerian hospitals; a notable one was the State Hospital network labeled "SHONET" that was developed to share resources such as personnel, laboratory and equipment over computer network in 2003 (Idowu, et al 2008). In 2004 another system was developed at the Computer Science \& Engineering, OAU, Nigeria. The system developed was used for referral of patients from one hospital to the other. This meant that patients' records usually recorded in case file, referral note and medical examination results could be transferred over the network (Idowu, et al 2004).

\section{Nursing Informatics}

Nursing informatics is a sub-category of health informatics formerly known as medical informatics (Idowu, Cornford \& Bastin, 2008). Based on literature, the term "nursing informatics" was first used and defined by Scholes and Barber in 1980 while addressing participants attending MEDINFO conference in Tokyo (Sewell \& Thede, 2013). There is still no definitive agreement on exactly what this term stands for. As Simpson (1998) once noted, defining nursing informatics appear difficult because the term was still evolving. The original definition said that nursing informatics was the use of computer technology in all nursing endeavors comprising nursing services, education, and research (Scholes \& Barber, 1980). Hannah, Ball, and Edwards (1994) proposed another early definition which followed the broad definition by Scholes and Barber. Hannah et al. (1994) defined nursing informatics as any use of information technologies in carrying out nursing functions. These two definitions placed emphasis on technology, like use of computers. The move from a technology direction to one the information orientated ones began in the mid 80s with Schwirian (Staggers \& Thompson, 2002). Schwirian (1986) created a model to be used as a framework by nursing informatics researchers. The model consisted of four elements arranged in a pyramidal form but with a triangular base. The top of the pyramid was made up of the desired goal while the base was made up of three elements: (1) users (practicing nurses and nursing students), (2) nursing information and (3) the technology made up of computer hardware and software (Figure 1). Next to this was the first widely circulated definition by Graves and Corcoran, who defined nursing informatics as "a combination of computer science, information science and nursing science designed to assist in the management and processing of nursing data, information and knowledge to support the practice of nursing and the delivery of nursing care" (Graves \& Cocoran, 1989; Staggers \& Thompson, 2002; Jensen, Meyer \& Sternberger, 2009). This definition established the position of nursing informatics within nursing practice, emphasizing nursing data, information, and knowledge (Staggers \& Thompson, 2002). A definition, many scholars have considered the "seminal" definition 
of nursing informatics. Turley (1996) added cognitive science; this places emphasis on the human factor in informatics. Goossen (1996), expanded the meaning of nursing informatics to include the thinking that is done by nurses to make knowledge-based decisions and inferences about patient care.

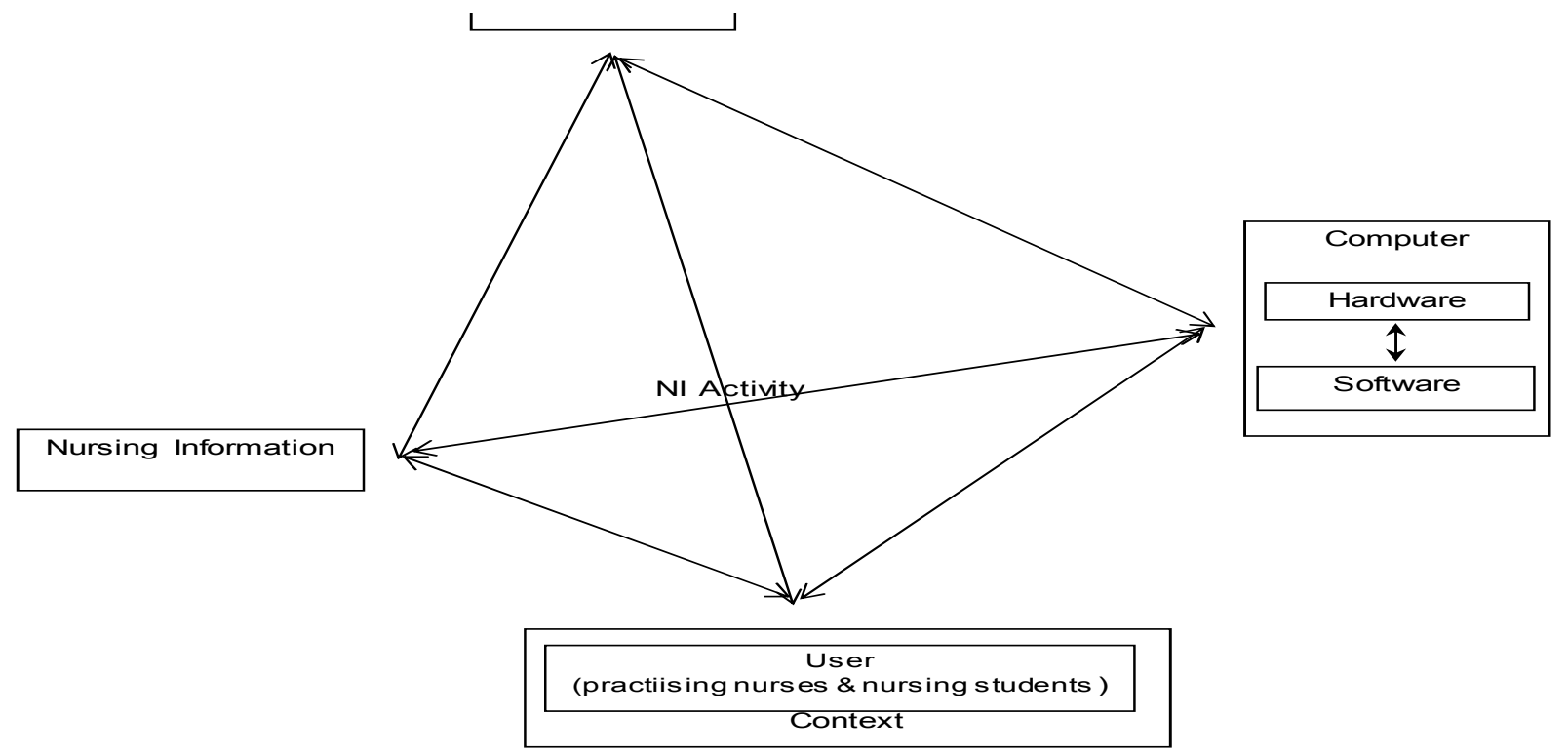

Fig. 1: Adapted from Schiwirian, P.M. (1986). Nursing Informatics pyramid

In $1992 \mathrm{NI}$ was recognized as a specialty by American Nurses Association (ANA). Subsequently, the definition was revised to take cognizance of the technology, conceptual and role orientations of many other existing definitions. The most recent definition mirror $\mathrm{NI}$ "as the specialty that integrates nursing science, computer science and information science to manage and communicate data, information, knowledge and wisdom to support patients, nurses, and other providers in their decision-making in all roles and settings. The support is accomplished through the use of information structures, information processes and information technology (Staggers \& Thomson, 2002; ANA, 2008; Gugerty \& Delaney, 2009). International Medical Informatics Association (IMIA)(2009) nursing informatics special interest group updated its definition to state that $\mathrm{NI}$ is "a science and practice which integrates nursing, its information and knowledge, and their management with information and communication technologies to promote the health of people, families and communities worldwide." The focus of nursing informatics is on information management in nursing which is applicable to nursing education, administration and practice (Sewell \& Thede, 2013).

\section{Components of Nursing informatics and required competencies}

The components/building blocks of $\mathrm{NI}$ implied in the seminal definition form the basis for the competencies. The building blocks of $\mathrm{NI}$ have been extensively discussed by Daniel and Oyetunde (2013). The necessity to manage complex quantity of data in patient care demands that all nurses, regardless of specialty area, have informatics skills (Gaumer, Koeniger-Donohue, Friel, \& Sudbay, 2007; Nelson, 2007). Although the nursing informatics specialty has many complex competency requirements in order to function effectively in the digital healthcare environment all nurses are required to have basic informatics skills (Tellez, 2012). Informatics skills for all nurses require basic computer skills as one component (American Nurses Association, 2008). Another skill needed for proficiency in informatics is information literacy. The ANA, NLN, and AACN have identified both computer and information literacy skills as necessary for evidencebased practice (Sewell \& Thede, 2013). Ronald and Skiba (1987) were the first to look at computer competencies required for nurses. In the late 90 s and early part of this century, this issue was revisited, but the focus became the use of computer skills as part of informatics skills (McCannon \& O'Neal, 2003; McNeil et al., 2003; Utley-Smith, 2004). Computer competencies means understanding basic computer \& computer technology information and vocabulary such as: PDAs, CPU, memory, software, proficiency in using computers and managing files, production of presentations, browsing the web. Information literacy refers to ability to recognize the nature and scope of information desirable, be able to access, utilize information appropriately and critically evaluate nursing information.

Four levels of informatics competencies have been defined for nurses. The first two levels are applicable to all nurses while the last two are relevant to informatics specialist nurses. Firstly, the novice nurse 
should have basic information management and computer technology skills. Other requirements include the ability to access data, use the computer for communication, use basic desktop software, and use decision support systems. Secondly, expert nurses should be skilled in using information management and computer technology to support their main area of practice. Additional skills for the experienced nurse include ability to make judgments on the basis of trends and patterns within data elements and to collaborate with nursing informatics nurses to make suggestion on ways of improving nursing systems. Thirdly, the informatics nurse specialist should be skilled in meeting the information needs of fellow nurses by combining and relating information, computer, and nursing sciences. Fourthly, the informatics innovator should conduct informatics research and generate informatics theory (Staggers, Gassert, and Curran 2001, 2002). According to ANA (2008), three informatics competencies should be ever present in nursing curricular namely, computer literacy, information literacy and professional development/leadership.

Canadian Association of Schools of Nursing, has defined three entry-to-practice nursing informatics competencies namely information and knowledge management, professional and regulatory accountability and information and communication technologies. Each competence is fitted with indicators. (CASN, 2012)

Information management means capability to collect data, process them and transform them into knowledge that can be used to advance clinical outcomes (Tellez, 2012). The use of standardized nursing language is important to define nursing phenomenon in terms of tasks, skills and knowledge (Jensen, Meyer \& Sternberger, 2009). It includes ability to capture clinical data in standardized electronical form which is subsequently transformed into information that is usable to improve health outcome (Tellez, 2012). Professional development/leadership entails "the ethical, procedural, safety and management issues for information solutions in nursing practice, education, research and administration" (ANA, 2008).

\section{Global and National issues in nursing informatics education}

In the United States, in 1996, National Advisory Council on Nurse Education and Practice, created the Informatics, national agenda for education and practice which made five recommendations as follows.

1. "Educate nursing students and practicing nurses on core informatics content.

2. Prepare nurses with specialized skills in informatics

3. Enhance nursing education and practice through informatics projects

4. Preparing nursing faculty in informatics

5. Increase collaborative efforts in nursing informatics" (Health \& Services, 1996)

In 2008, the National League for Nursing (NLN) published a position paper which outlined the recommendations for preparing nursing faculty, deans/ directors/chairs and NLN to work in an environment utilizing technology. Among the recommendations was the need for faculty to acquire competencies in informatics and inclusion of informatics into the nursing curriculum. The American Association of Colleges of Nursing (AACN) formed a list of core competencies which include use of information and communication technologies, use of ethics in the application of technology and enhancement of one's knowledge through information technologies (AACN, 2006, 2008, 2011)

Formal nursing training in Nigeria started in 1946 with the establishment of the Nursing Council of Nigeria. Nursing education takes into consideration the National policy on education for developing sound principles which are important to the preparation of nurses to function, independently/interdependently as members of interdisciplinary/intersectoral teams (Adebanjo \& Olubiyi, 2008). Nursing education is at various levels in Nigeria, the first level is the basic nursing/midwifery level which leads to the award of the Registered Nurse (RN)/Registered Midwife (RM) certificate, the second level is made up of the post basic programmes in Midwifery, Opthalmic/Perioperative/Psychiatry/Public health/ Orthopaedic nursing programmes. These programmes lead to specialization in Nursing. Next to this are first degree programmes which is obtainable either part/full time or as a distant learning programme or at the National Open University of Nigeria (NOUN). A few Universities currently run Masters and PhD programmes in nursing as well. Nursing education at the basic and post-basic levels is regulated by the Nursing and Midwifery Council of Nigeria (N\&MCN) while undergraduate and postgraduate/graduate programme are jointly regulated by National University Commission (NUC) and N\&MCN. West African Health Examination Board (WAHEB) regulates post basic public health programmes in collaboration with N\&MCN. The past decade has witnessed significant increase in the use of electronic media in educational settings in most developed countries. It has been affirmed that computer technologies have opened the door to many new teaching approaches to nurse educators. Cuing into this development will be of great advantage to the nursing education system in Nigeria (Axley, 2008).

The Nursing education system should produce graduates that are well equipped to work in an evolving highly technological environment. This calls for integration of Information Communication Technology (ICT) into nursing education curricula at all levels. In line with this the Nursing and Midwifery Council of Nigeria revised the curriculum for General Nursing and Midwifery in 2013. Information Communication Technology (ICT) and Use of computers in Midwifery Practice courses were added to the basic Nursing and Midwifery curricular respectively (NMCN, 2013a; NMCN, 2013b). The National Universities Commission (NUC) also mandated all Universities in Nigeria to include introduction to computers and computer programming as one of the undergraduate courses. In addition to this a few Universities have nursing informatics courses integrated into their curriculum. The courses expose students to theoretical and hands on experiences on computer science. Furthermore, both NUC and N\&MCN has stipulated in their minimum accreditation requirement for basic and undergraduate nursing programmes, provision of adequate number of computers in Schools/Departments of nursing/midwifery 
and linkage of the institutions to internet facilities. It should be noted that although these efforts are in the right direction, nursing informatics is not just computer science, word processing, clinical documentation or use of the internet (ANA, 2008). A study carried out among 540 nursing deans/directors and 1557 faculty revealed that online course offerings and information literacy skills were wrongly equated to informatics (NLN, 2008). The Nigerian Association of University Nursing Programmes (NAUNP) at its $10^{\text {th }}$ National Scientific conference, focused on nursing informatics as the cutting edge for modern day nursing. This was to create awareness and update nurse academics' knowledge about nursing informatics (NAUNP, 2014). A comprehensive nursing informatics agenda is therefore required for Nigeria to address students' needs at all levels as well as faculty needs. A descriptive study which examined Nursing Informatics (NI) preparedness of graduate nurses in Calabar, Nigeria reported that only $51.0 \%$ of nurse educators were knowledgeable about nursing informatics while only $25(24.8 \%)$ of the respondents considered their level of computer literacy adequate (Akpabio \& Ella, 2014) Importantly, the practice settings should be well equipped to give opportunities to nursing students to practice in an ICT compliant environment, which is largely lacking in most health institutions in Nigeria. The practitioners who should mentor the students too should have basic informatics competencies.

\section{Importance and benefits of utilizing nursing informatics tools in nursing education in Nigeria}

The use of informatics tools in the teaching learning process is valuable for both nurse educator and nursing student alike. From the perspectives of nurse educators, the tools will enhance preparation and delivery of information to nursing students in the lecture hall and the clinical setting.

It is expected that effectiveness of classroom teaching will be improved through Microsoft power point presentation which will facilitate learning among nursing students at all levels. In addition, the use of open source application such as customizable E-learning tools students' assessment, critical thinking exercises, graphical illustrations and interactive video technology (telenursing) should make the teaching-learning process appealing and more impactful. Use of ICT makes the teaching materials much more engaging, thus making the students more attentive and focused. For instance, use of multimedia instruction combined with visuals, animations and audio aid in achieving this effect. The use of video is particularly valuable in teaching clinical procedures such as bed making, bed bathing, cardiopulmonary resuscitation, open heart surgery. It gives the learner, a much better understanding and appreciation of the actual clinical situation. Teaching through video increases the level of encoding and results in better recall by students.

Besides, the tools should broaden the researchbased activities of the educators, such as identification, retrieval and evaluation of information from open access peer review journals, statistical sources and the internet.

Similarly, access to a broad range of materials, which were not previously available to students, should be possible by using the PC following nursing informatics education. For example, using the PC for internet search, students should be able to gather information that is current and relevant to tasks at hand rather than using old outdated, traditional resources.

Independent learning on the part of the students with personal computers (PC) will also be promoted. A notebook with wireless access means that students can study virtually anywhere on campus and are not restricted to the library. Brain storming or collaborative sessions can therefore take place anytime, anywhere, ensuring better learning and better grades. A better understanding of the nursing process for client care is expected to be achieved when students learn to navigate the electronic health record, acquire information at point of learning, find evidence and create a plan of care based on credible data/ information. Besides, students would have developed skills to source for jobs offers/opportunities online, on graduation, web based courses, distance learning programmes.

The benefits of nursing informatics education for nursing students cannot be overestimated, the significance include transformation of education through richer course content, improved access to information and new learning methods that take advantage of independent, collaborative and interactive technique.

\section{Challenges of Nursing Informatics Education in Nigeria}

The introduction of new ideas into a system is not devoid of challenges; occurrence of revolutions is inevitab1e because majority of nursing education institutions in Nigeria were not established during the computer age and were operating with the traditional resources, such as blackboard and chalk initially which gave way to whiteboard and dry whiteboard marker pens in recent times. A few schools have gone a step further to introduce the use of flipcharts, overhead projectors and transparencies.

However, teaching process using power-point presentations are being introduced and electronic communications, through e-mail/Skype are gradually being adopted. Alongside is the problem of acute shortage of nurse educators. This is evidenced by redeployment of retired nurse educators into both basic and post basic schools of Nursing in some States of Nigeria (Personal communication, 2009).

The application of technology in teaching is a learned skill not an intuitive one; and it involves considerably more knowledge and skill than knowing how to use a computer. Programmes are therefore, needed to enable nursing education institutions in Nigeria to incorporate technology into their repertoire of teaching strategies.

Today's expectation that institutions will use electronic technologies in their teaching can be particularly stressful for the staff in nursing institutions with little or no computer knowledge. This can be compounded when an educator is teaching many nursing students who have grown up in the computer age. These students are often referred to as the "net generation" based on their digital literacy and the need to be electronically connected.

The additional burden on the already stressed nurse educator(s) of mastering new advances in technology and developing electronic courses could 
potentially hasten the departure of many highly qualified staff from nursing education institutions, thus exacerbating the already existing manpower shortage. Integration of technology into nursing education requires educators who are prepared to facilitate an effective learning experience. But the big question remains "Who is prepared to teach the teachers how to integrate technology into the curriculum"? There was a recent workshop on Integrating Technology into nursing curriculum. 'How many educators were privy to attending this workshop? How many trainee trainers were produced? This remains a big challenge coupled with incessant power outage.

The use of technology in healthcare is now being advocated which requires informatics competent nurse workforce. By implication, nursing education now, has and will have no choice but to prepare nursing students in as many ways as possible to work in a highly technological environment. According to Abbot (2001) it is a crime to graduate nursing students who do not know how to interact in this complex technology rich environment. Informatics competent nurses educators will be required to train such nurses.

Nursing is not alone in the struggle with technological revolution in education. The infusion of technology into higher education is being adopted in Nigeria in many other areas. In many Universities, Departments use the computer to conduct tests and examinations, post University Matriculation examination is now conducted by some Universities using computers. Application for admission and registration into some secondary and tertiary educational institutions now cue into the use of technology. The Nursing and Midwifery Council of Nigeria is also registering students for the professional examinations on-line. The challenge is what is the level of preparedness of nursing students, faculty members and Department of Nursing for these innovations?

Furthermore, there is paucity of studies in this area to address many of the problems begging for answers on which to base a credible informatics agenda for Nigeria. For instance what are nurse educators' perceptions of the gaps in the Nigerian nursing education curricula that should be filled to produce informatics competent nurses who can function effectively in the practice setting? How many health facilities have the required IT infrastructure that could be used to prepare graduate nurses to meet the $21^{\text {st }}$ century consumer demands for nursing practice?

\section{Prospect of Nursing Informatics Education in Nigeria}

There is no doubt that advocacy for integration of technology into nursing curricula will pose great challenges to nursing education institutions in Nigeria. But the good news is that faculty members/nurse educators recognize that lifelong learning is a reality hence the need to step up and join the reform rather than risk becoming obsolete. Many have engaged/are currently engaging in self-development to ensure that they acquire the required technological competence. Some faculty members have acquired computer literacy through governmental/institutional support.

But as earlier observed, teaching with technology involves more skill than just knowing how to use a computer. It calls for capacity building of faculty members in technology-related teaching skills. The "Technology Fellowship Programme" (TFP) recommended by Axley (2008) which featured collaboration with other faculty members could be useful. The author emphasized that collaboration with faculty teaching the pre-nursing science courses was an added benefit of participation in the TFP. Furthermore, observation of the collaborative teaching-learning process allowed for reorganization of nursing students' to use the electronic courseware prior to taking nursing courses. This made the students to become more comfortable with the technology used. Besides as a group, the TFP participants were supportive of new ideas and challenged one another to think in nontraditional ways. Members acknowledged similarities in their zeal and quest for innovative teaching strategies and shared their teaching philosophies, strategies and student evaluation methods.

The nurse educators need experts as mentors to provide guidance on how to acquire knowledge and skills on "intellectual use" of information technology. On their own part, faculty members should be eager to receive mentorship in the courses assigned to them every semester. Mentors ought to engage colleagues in such a way as to promote success, enhance learning, and provide crucial feedback and guidance without creating a sense of in security. These can be drawn from Senior Colleagues who have undertaken the course previously and informaticists from Obafemi Awolowo University and Obafemi Awolowo Teaching Hospital, Nigeria where informatics started in Nigeria (Idowu et al, 2003). Congelosi (2004) highlighted the characteristics of mentors as generosity, competence, self confidence and commitment to the relationship. Elements of inspiration, nurturing, and taking time to focus on the individual are key to successful mentoring (Smith and Zsohar 2007). Mentoring therefore demands the provision of an environment that allows for a fluid exchange of information and ideas, and concerns. Although there is no health informatics policy for Nigeria, the national technology policy Bill is before the National Assembly for legislation (Ohanyido, 2012)

The steps of $\mathrm{NI}$ include assessment, diagnosis, outcome identification, planning, implementation and evaluation. Assessment phase includes the use of nursing informatics models which defines goals that are measurable. In NI, diagnosis includes use of standardized nursing terminology which could be based on North America Nursing Diagnosis Association (NANDA) taxonomy / ICNP (International Classification of Nursing Practice by ICN NHO - available at ICN C space). Planning, implementation and evaluation entails use of Nursing Outcome Classification \& Nursing Intervention Classification (Goossen, 2008). Nigerian Nurses are already versed in the use of the nursing process; hence it will be easy for them to adapt the process for documentation.

\section{RECOMMENDATIONS}

Nursing and Midwifery Council of Nigeria (N\&MCN) in collaboration with National Universities Commission (NUC) and National Association of Nigerian Nurses and Midwives (NANNM), NAUNP and other regulating agencies should reach an agreement on the 
definition of nursing informatics to be adopted for Nigerian nurses, the minimum informatics competencies for practice in the $21^{\text {st }}$ century in Nigeria and a national agenda/framework for integrating nursing informatics into the nursing education system in Nigeria.

This should be based on evidence; hence a task force or national committee could be set up to conduct need and feasibility assessments, quality management and customer satisfaction studies. Other relevant information include availability of infrastructure for implementation of $\mathrm{NI}$ in educational and health institutions in Nigeria, current level of integration of $\mathrm{NI}$ in the Schools/ Departments of Nursing and faculty members'/nurse educators current level of readiness to impact informatics knowledge and skills to their students. The N\&MCN could use its sub-committees such as research and education to kick start the process. The bodies should mobilize resources both internally and externally for informatics training of nurse faculty, educators and practitioners. The nurse faculty/educator should collaborate with clinicians and informatics expert in the clinical setting to help practionners and students develop NI competencies.

The demands of a technology rich learning environment increases the need to bridge the generational gap between educators and today's learners who are living and learning in a supersonic age. Urgent action is therefore required to retain highly qualified nurse educators through exposure to development programmes focusing on achievement of informatics competency. It therefore, becomes a compelling need for technological competency among nurse educators to be acknowledged and recognized.

There is also need to design structured programmes to build capacity of nurse educators/faculty to use technological advances in their teaching. With the impetus to expand the use of technology, nurse educators should be prepared to use available resources, have access to needed support, and develop competency for using resource and support throughout the curricula. Nurse educators/faculty should incorporate informatics and NANDA standardized nursing language and terminology into the nursing curricula at all levels.

Deans and Directors should provide leadership in acquiring the required IT infrastructure in the institutions including the clinical setting to prepare nursing students adequately for practice in an IT rich environment. They should advocate that all nursing students should possess knowledge and skills in computer, information literacy and informatics. They should also advocate for adequate budgetary allocation to IT activities.

Most institutions in the developed countries have identified the need to enhance the availability of technology and promote the development of online courses and degree programmes. Some institutions in Nigeria are making efforts to key into this and the nursing profession should also key into this initiative. Nursing education administrators have to endorse ongoing development and involvement in the area of distance education and learning of technology in the teaching learning process as is currently used in the Open University system of Education in Nigeria.

\section{CONCLUSION}

Currently, nursing informatics in Nigeria is still in its infancy. Nursing education in Nigeria uses mostly traditional instructional strategies to deliver instruction to students. Most teaching is in abstraction with lots of time spent in explaining and dictating long lecture notes. The application of technology in nursing education in Nigeria is an innovation that will allow more choices, enhance faculty-student interaction, and bring about variation in learning. Neuman (2006) observed that technology had changed the face of traditional nursing education.

Recent worldwide trends suggest wider use of informatics in nursing curricula to improve the quality of nursing education. The emerging rise in the use of technology demands that nursing Schools, Colleges and Departments adopt ICT in the teaching-learning process. Simborio (as cited in Intel, 2010), emphasized that the growth of ICT in higher education is showing that traditional instruction is slow, time consuming and provides limited access to information. Its use should therefore be de-emphasized in nursing education. The use of ICT in classroom teaching as earlier highlighted is dynamic, innovative and creative; it also extends students learning experience to any location with access to a wireless network.

It is therefore no longer an optional choice for use in the teaching-learning process in nursing education. Nurse educators who are vested with the responsibility of producing competent nurses, well suited to function in highly technological environment should endeavour to be digitally literate in spite of the impediments. In this way, they will significantly change the existing teaching strategies in nursing education.

According to Saba (2001), technological revolution is here to stay and should be embraced by all nurses regardless of area of specialization. The rapid growth of the digital age will certainly continue; therefore faculty development is crucial in ensuring that nursing education administrators and faculty alike enhance students' learning and retains faculty members.

Finally, it is expedient that in line with demands of the Nursing and Midwifery Council of Nigeria, nursing curricula at all levels of nursing education should provide a well furnished computer laboratory with desk top computers, software and up-to-date resources that will promote digital literacy and effective learning.

\section{REFERENCES}

Abbot, P., 2001. In John Hopkin's and Eclipses announcement at John Hopkin's University School of Nursing in Baltimore, Maryland, USA.

Adebanjo, F and Olubiyi, K., 2008. Reforms in nursing education: The national open University of Nigeria experience. Retrieved August 01, 2015, from www.nou.edu.ng

Akpabio, I. I and Ella, R. E., 2014. Nursing Informatics Preparedness of Graduate Nurses in Calabar, Nigeria. A paper presented at the $10^{\text {th }}$ National Scientific conference: Nigerian Association of University Nursing Programmes (NAUNP). 
Retrieved July 10, 2015 from www. Researchgate.net/..../270784787.

American Association of Colleges of Nursing., 2006. The essentials of doctoral education for advanced nursing practice. Retrieved July 28, 2011, from http://www.aacn.nche.edu/DNP/pdf/ Essentials.pdf

American Association of Colleges of Nursing., 2008. The essentials of baccalaureate education for professional nursing practice. Retrieved June 10, 2010, from http://www.aacn. nche.edu/education/pdf/ bacce ssentials08.pdf

American Association of Colleges of Nursing., 2011. The essentials of master's education in nursing. Retrieved July 10, 2015, from http:// www. aacn. nche.edu/Education/pdf/Master'sEssentials11.p df

American Nurses Association., 2008. Nursing informatics: Scope and standards of practice, Silver Springs, MD, American Nurses Association. P.65.

Anja, M., 2002. Information system development in developing countries, risk management and sustainability analysis in Nigeria software companies, ed. by S. Puuronen (Department of Computer Science and Information Systems, University of Jyvaskyla, Marja-Leena Tynkkynen and pekka Olsbo, 27-54.

Arikpo, I., Mboto, I., Okoro, A., James, U., Aquaisus, E., nwa, K., Usie, M., Enang, E., Esu, E., M Asangasi, I and Meremikwu, M., 2013. Optimum hardware, software and personnel requirements for a paperless health and demographic survellannce system: a case study of Cross River HDSS, Nigeria. Information and knowledge management, 3, (3): 77- 83.

Axley, L., 2008. The integration of technology into nursing curricula: Supporting faculty via the technology fellowship program. OJIN: The Online Journal of issues in Nursing, 13, (3): 1 12.

Canadian Association of Schools of Nursing., 2012. Nursing Informatics Entry-to-Practice Competencies for Registered Nurses. CASN.

Congelosi, P. R., 2004. A lack of qualified faculty: One school's solution: Nurse Educator. 28, 186-188.

Delaney, C., 2001. Health informatics and oncology nursing. Seminars in Oncology Nursing, 17, (1): 2-6.

Daini, O., Korpela, M., Ojo, J and Soriyan, H., 1992. MEDIFO. Amsterdam. The computer in a Nigerian teaching hospital: First year experience; pp. 230-5.
Daniel, O. G and Oyetunde, M. O., 2013. Nursing Informatics: A key to improving nursing practice in Nigeria. International Journal of Nursing \& Midwifery, 5, (5): 90-98.

Goossen, W. T. F., 1996. Nursing information management and processing: A framework and definition for systems analysis, design, and evaluation. International Journal of Bio-Medical Computing, 40:187-95. [PubMed]

Graves, J. R and Corcoran, S., 1989. The study of nursing informatics. image: The Journal of Nursing Scholarship, 21, (4): 227-231.

Gugerty, B and Delaney, C., 2009. Tiger Technology informatics guiding educational reform (TIGER) Initiative. Informatics Competencies Collaborative (T1CC) Final Report 2009.

Federal Ministry of Health (FMOH)., 2014. National Health Information System Strategic Plan 2014 2018. $\mathrm{FMOH}$.

Hannah, K. J., Ball, M. J and Edwards, M. J., 1999. Introduction to Nursing Informatics ( $2^{\text {nd }}$ ed.). Springer New York, 171- 188.

Health, U. D. O and Services, H., 1996. National Advisory Council on Nurse Education and Practice; Report to the Secretary of Health and Human Services on the Basic Registered Nurse Work Force. Washington, DC: US Government Printing Office.

Mandil, S. H., (Ed.). 1993. Health Informatics in Africa: HELINA 93: First International Conference on Health Informatics in Africa, Ile-Ife, Nigeria, 1923 April, 1993 (Vol. 1055). Excerpta Medica.

Mandil, S. H., Moidu, K., Korpela, M., Byass, $P$ and Forster, D., 1993. Health Informatics in Africa-HELINA 93: Proceedings of the First International Conference. Ile-Ife, Nigeria.

National League for Nursing (NLN)., 2008. Position statement: Preparing the next generation of nurses to practice in a technology-rich environment: An informatics agenda. Retrieved July 10, 2015, from http://www.nln.org/aboutnln/ Position Statements/informatics_052808.pdf

Idowu, P. A and Ajayi, A. S., 2008. GSM based referral system for primary health care centers in Nigeria. International Journal of Soft Computing, 3, (6): 421-427.

Idowu, P., Cornford, D and Bastin, L., 2008. Health informatics deployment in Nigeria. Journal of Health Informatics in Developing Countries, 2, (1):

IDRC/CRDI., 2013. Governance for equity in Health System. Retrieved July 15, 2015 fromhttp://www.idcr.ca/EN/Programs/Socialand 
economic Policy/Governance for Equity in $\mathrm{He}$ alth_Systems.

International Medical Informatics Association (IMIA)., 2009. Nursing informatics special interest groupdefinition. Retrieved June 15, 2015 from http://www. imiani. origindex. phpoption =com content \& task=view\&id=27\&ltemid=5.

INDEHELA., 1989. Informatics Development for Health in Africa. Retrieved June 15, 2015 from http://www.uku.fi/indehela/.

Nursing and Midwifery Council of Nigeria., $2013 a$. Curriculum for general nursing education revised, p.46.

Nursing and Midwifery Council of Nigeria., 2013b. Basic Midwifery Curriculum for Nigeria, revised, p.53.

Ohanyido, F., 2012. Health Informatics: A Bird's eye view of Nigeria. A paper presented at the West African Health Informatics Fellowship Programme (WAHIFP) Inauguration, January, 2012.

Quinin, F. M., 2000. Principles of practice of nurse education $\left(4^{\text {th }}\right.$ ed.) Cheltenham: Stanley Thornes Publishers Ltd.

Saba. V. K., 2001. Nursing informatics: yesterday, today and tomorrow, International Nursing Review, 48, $177-187$

Sewell, J and Thede, L. Q., 2013. Informatics and Nursing: Opportunities and Challenges. $\left(4^{\text {th }}\right.$ ed.). Philadelphia. Lippincott Williams \& Wilkins.

Severs, M and Pearson, C., 1999. Learning to manage health information: a theme for clinical education: NHS Executive, Bristol.

Schwirian, P. M., 1986. The Nursing Informatics pyramid, a model for research in nursing informatics. Computer Nursing, 4, (3): 134-136.

Shortliffe, E. H and Blois, M. S., 2001. The computer meets medicine: Emergence of a discipline. In E.H. Shortliffe \& L.E. Perrault (eds.), Medical informatics: Computer applications in healthcare (pp.3-40). New York, NY:Springer-Verlag.

Shortliffe, E. H and Blois, M. S., 2006. The computer meets medicine and biology: emergence of a discipline Biomedical Informatics (pp. 3-45): Springer.

Staggers, $\mathrm{N}$ and Thompson, C. B., 2002. The Evolution of Definitions for Nursing Informatics A Critical Analysis and Revised Definition. Journal of the American Medical Informatics Association, 9(3), 255-261.

Idowu, P., Cornford, D and Bastin, L., 2008. Health informatics deployment in Nigeria. Journal of
Health Informatics in Developing Countries, 2(1).

Intel World Ahead., 2010. Information and Communication Technology (ICT) is transforming Healthcare Education in the Philippines. Retrieved September 12, 2014 from http:// www.who.int /pmnch/media/news

Jensen, R., Meyer, L and Sternberger, C., 2009. Three technological enhancements in nursing education: Informatics instruction, personal response systems, and human patient simulation. Nurse education in practice, 9, (2): 86-90.

Shortliffe, E. H and Blois, M. S., 2006. The computer meets medicine and biology: emergence of a discipline Biomedical Informatics (pp. 3-45): Springer.

Smith, J. A and Zsohar H., 2007. Essentials of neophyte mentorship in relation to the faculty shortage. Journal of Nursing Education, 46, (4): 184-186.

Staggers, N and Bagley Thompson, C., 2002. The evolution of definitions for nursing informatics: A critical analysis and revised definition. Journal of the American Medical Informatics Association, 9, (3): $255-262$.

Tellez, M., 2012. Nursing informatics education past, present, and future. Computers informatics Nursing, 30(5), 229-233. 